\title{
Assessing Patient Readiness for the Clinical Adoption of Personalized Medicine
}

\author{
A.M. Issa ${ }^{a-c} \quad$ W. Tufail ${ }^{a} \quad J$. Hutchinson $^{d} \quad J^{T_{\text {Tenorio }}}{ }^{c} \quad$ M. Poonam Baliga ${ }^{a}$ \\ a Program in Personalized Medicine and Targeted Therapeutics, ${ }^{b}$ Department of Pharmacological \\ and Pharmaceutical Sciences, College of Pharmacy, ${ }^{\mathrm{C}}$ The Methodist Hospital Research Institute, and \\ ${ }^{\mathrm{d}}$ Department of Anthropology, University of Houston, Houston, Tex., USA
}

\section{Key Words}

Clinical adoption · Focus groups • Patient acceptance •

Personalized medicine $\cdot$ Pharmacogenomics

\begin{abstract}
Background/Aims: Although pharmacogenomics-based diagnostics and therapeutics are increasingly being translated into personalized medicine applications, relatively little evidence exists about how novel pharmacogenomics-based technologies will be accepted and adopted by patients. It is important to understand the characteristics of genomic diagnostics and targeted therapeutics that might impact utilization or serve as barriers to adoption of these novel technologies in order to formulate appropriate policies and procedures. The objective of this study was to investigate patients' understanding and knowledge of personalized medicine and the process of decision-making regarding pharmacogenomics testing and targeted therapeutics and to better understand how patients value receiving pharmacogenomics-based care. Methods: We conducted 4 focus groups with 8-10 individuals in each group with patients recruited from out-patient clinics at The Methodist Hospital in Houston, Tex., USA. Results: The use of genomic diagnostics and targeted therapeutics to facilitate personalized medicine has considerable support from patients. However, our
\end{abstract}

data revealed that participants were concerned with issues surrounding privacy and confidentiality of genetic test results, particularly with respect to access of information by insurers, with potential costs of testing and issues related to accuracy of test results. Questions regarding willingness to pay revealed that patients would be more willing to pay outof-pocket if the disease associated with pharmacogenomic testing for treatment was perceived to be high risk (e.g., colorectal cancer) versus a chronic condition that was perceived as lower risk (e.g., high cholesterol). Conclusion: As the personalized medicine approach is increasingly incorporated into health care, understanding patients' needs and their readiness to adopt these novel technologies will become progressively more important for the development of appropriate health policies. Copyright $\odot 2009$ S. Karger AG, Basel

Personalized medicine is the translation of the science of pharmacogenomics into clinical practice. Personalized medicine involves preventative, diagnostic, and therapeutic interventions, with risk defined through genetics as well as clinical and family histories. There are already several well-known examples of personalized medicine based upon using pharmacogenomics [1-8]. However, pharmacogenomic-based diagnostics and ther-

\section{KARGER \\ Fax +41613061234 \\ E-Mail karger@karger.ch}

www.karger.com
(C) 2009 S. Karger AG, Basel

$1662-4246 / 09 / 0123-0163 \$ 26.00 / 0$

Accessible online at:

www.karger.com/phg
Amalia M. Issa, PhD

MPH Program in Personalized Medicine and Targeted Therapeutics

University of Houston, 300 Technology Building

Houston, TX 77204-4021 (USA)

E-Mail aissa@uh.edu 
apeutics have not yet been fully incorporated into routine clinical practice.

The increasingly swift pace of technological development in genomics science could lead to the endorsement and adoption of pharmacogenomic-based diagnostics and therapeutics without sufficient examination of their potential impact [9] and whether patients are ready to adopt personalized medicine based upon pharmacogenomics. It is important to understand the characteristics of genomic diagnostics and targeted therapeutics that might impact utilization or serve as barriers to adoption of these novel technologies in order to formulate appropriate policies and procedures.

This study was aimed at examining patients' understanding and knowledge of personalized medicine and the process of decision-making regarding pharmacogenomics and targeted therapeutics and how patients value receiving pharmacogenomics-based personalized health care relative to the standard models of diagnosing and prescribing treatments.

\section{Methods}

As part of a larger project, we opted to use focus groups to explore patients' understanding and decision-making about the use of personalized medicine applications in clinical practice, because the use of focus groups is a well-validated methodology [10, 11] and is particularly appropriate for nascent emerging technologies that are not yet offered routinely as health care services.

We conducted 4 focus groups with 8-10 individuals in each group. An experienced moderator (J.H.) facilitated each group. With participants' knowledge and consent, the principal investigator (A.M.I.) observed and made field notes during each focus group to assess group dynamics and process. Potential participants were recruited by a trained Research Study Coordinator (J.T.) from patients receiving care at the internal medicine practices of The Methodist Hospital to ensure diversity among participants. These internal medicine clinics routinely care for a diverse group of adults many of whom have chronic medical conditions such as diabetes mellitus, hypercholesterolemia, and hypertension, drawn from the greater Houston metropolitan area, the 4th largest city in the United States. Purposeful sampling was used to recruit patients into the final focus groups. The primary eligibility criteria for participation were to be English-speaking adults aged 18 or older who have recent experience with the health care system and are fit to participate in a focus group. Any patient with psychological, psychiatric, or severe physical medical conditions was excluded from participation.

The protocol for each group consisted of participants initially being welcomed, the study verbally explained, and written informed consent given by each participant. Participants then completed a short questionnaire to provide sociodemographic information about the composition of each group. To facilitate the discussion, a semi-structured interview guide was used. The in- terview protocol focused on (1) exploring what terms and wording are most understandable to respondents and (2) probing for understanding and factors that influence preferences for pharmacogenomic-based tests and drugs. Issues that were explored included those related to the process of testing (including test sensitivity and specificity, duration of testing and time that it takes to obtain results, and access to testing), costs of testing and of targeted therapies, and how the information provided by testing influences decision-making. Patients were also presented with hypothetical, but realistic, scenarios about 2 common medical conditions with which participants would have familiarity: hypercholesterolemia and colorectal cancer.

Each focus group lasted between 90 to 120 minutes. With participant consent, each group was audio-recorded and written transcripts created verbatim from the recordings of all focus groups. Guided by a grounded theory approach, these written transcripts were analyzed and coded into themes [11, 12] by all authors, and any disagreements were resolved by consensus. No major inter-rater inconsistencies were found.

Participants received gift cards in the amount of $\$ 40$ to compensate them for their time and vouchers for parking. Light refreshments were provided.

This study and all materials were approved by The Methodist Hospital Research Institute's Institutional Review Board and University of Houston's Committee for the Protection of Human Subjects.

\section{Results}

Focus groups (FG) were conducted in a conference room at The Methodist Hospital during the fall of 2007. Thirty-two out-patients participated in the focus groups (53\% were men and $46 \%$ were women; $60 \%$ ranged in age from 45 to 64 years old). The sociodemographic characteristics are presented in table 1. Several themes emerged from the data, and the key themes are presented in table 2 .

\section{Understanding of Pharmacogenomics and \\ Personalized Medicine}

Most participants expressed an awareness and understanding of the term personalized medicine, which they had predominantly obtained through media sources including newspaper articles, radio, and television stories. There was less familiarity with the term pharmacogenomics. Following group discussion to probe for understanding, participants were presented with a lay definition of the terms pharmacogenomics (i.e., 'the science that allows us to predict a response to drugs based on an individual's genetic make-up. In other words, it is using genetic tests to determine how you will respond to a drug.') and personalized medicine (i.e., 'the application of pharmacogenomics to prescribe drugs that are tailored to pa- 
Table 1. Sociodemographic characteristics of focus group participants

\begin{tabular}{|c|c|}
\hline Characteristic & Percent \\
\hline \multicolumn{2}{|l|}{ Age } \\
\hline $25-44$ & 39 \\
\hline $45-64$ & 61 \\
\hline \multicolumn{2}{|l|}{ Sex (gender) } \\
\hline Male & 54 \\
\hline Female & 46 \\
\hline \multicolumn{2}{|l|}{ Race/Ethnicity } \\
\hline Caucasian (White) & 66 \\
\hline Black or African-American & 20.7 \\
\hline Hispanic/Latino or Asian & 13.3 \\
\hline \multicolumn{2}{|l|}{ Marital status } \\
\hline Single/never married & 12.5 \\
\hline Married & 63.5 \\
\hline Divorced & 24 \\
\hline \multicolumn{2}{|l|}{ Education } \\
\hline High school diploma/G.E.D. & 7 \\
\hline Some college & 26.7 \\
\hline Bachelors degree & 40 \\
\hline Masters degree & 23.3 \\
\hline Doctoral degree (PhD/other) & 3 \\
\hline \multicolumn{2}{|l|}{ Income, USD } \\
\hline 25,000 or less & 16.7 \\
\hline $26,000-50,000$ & 20.6 \\
\hline $51,000-75,000$ & 16.7 \\
\hline $76,000-100,000$ & 20 \\
\hline Over 100,000 & 26 \\
\hline \multicolumn{2}{|l|}{ Decisions about your healthcare } \\
\hline Myself & 80 \\
\hline Spouse & 6.7 \\
\hline Other (e.g., both) & 13.3 \\
\hline \multicolumn{2}{|l|}{ Health insurance } \\
\hline Yes & 76 \\
\hline No & 24 \\
\hline
\end{tabular}

tients based on their genetic information, as well as their clinical and family histories') to clarify understanding and stimulate discussion.

Participants in all 4 focus groups demonstrated a limited understanding of how genetic variation plays a role in drug metabolism, drug responsiveness, and toxicity, and how environmental interactions also play a role. Indeed, only 5 participants suggested that environmental influences may be relevant.

'Well, the drug may not have caused the reaction. Something else may have caused the reaction. Something you ate, or what if the food does not agree with the medication you are taking? And it may cause a reaction also.' (FG 2)
Table 2. Key themes and associated sub-themes identified in the study

\begin{tabular}{|c|c|}
\hline Key theme & Sub-themes \\
\hline $\begin{array}{l}\text { Understanding } \\
\text { of pharmaco- } \\
\text { genomics and } \\
\text { personalized } \\
\text { medicine }\end{array}$ & $\begin{array}{l}\text { Source of information } \\
\text { Understanding/misunderstanding of } \\
\text { information }\end{array}$ \\
\hline $\begin{array}{l}\text { Experiences } \\
\text { with } \\
\text { conventional } \\
\text { prescribing }\end{array}$ & $\begin{array}{l}\text { Trial and error } \\
\text { Effectiveness } \\
\text { Adverse drug reactions (side effects) } \\
\text { One-size fits all }\end{array}$ \\
\hline $\begin{array}{l}\text { Pharmaco- } \\
\text { genomic- } \\
\text { based testing }\end{array}$ & $\begin{array}{l}\text { Physical discomfort of testing } \\
\text { Duration of testing } \\
\text { Validity of tests } \\
\text { Reliability of tests } \\
\text { Time to results from testing } \\
\text { Access to testing } \\
\text { Privacy confidentiality of test results } \\
\text { Disclosure issues (insurance, employer, family) } \\
\text { Severity of disease/condition } \\
\text { Consumer demand } \\
\text { Risks } \\
\text { Cost } \\
\text { Insurance } \\
\text { Willingness to pay (WTP) }\end{array}$ \\
\hline $\begin{array}{l}\text { Targeted } \\
\text { therapeutics }\end{array}$ & $\begin{array}{l}\text { Effectiveness (cure vs. slow progression vs. no } \\
\text { clinically significant difference in treatment) } \\
\text { What exactly is the therapy doing to the body } \\
\text { (better absorption; more tailored) } \\
\text { Adverse events (side-effects) } \\
\text { Provides options for decision making } \\
\text { regarding treatment } \\
\text { Prevention } \\
\text { Expressed preference for personalized medicine } \\
\text { Availability of treatment based on genetic } \\
\text { information } \\
\text { Cost of treatment } \\
\text { Quality of life } \\
\text { Access to treatment } \\
\text { Compliance and adherence }\end{array}$ \\
\hline
\end{tabular}

\section{Expectations of Personalized Medicine: Benefits}

Approximately $68 \%$ of patients generally indicated a preference for the use of pharmacogenomic-based testing for the purpose of improving drug prescribing and associated health outcomes. Discussion centered on concerns related to experiences with adverse drug reactions and the potential for pharmacogenomics to overcome or minimize the problem of adverse drug reactions.

Public Health Genomics 2009;12:163-169 
'When you're trying to find the right treatment, you're wanting results immediately and here you are going through side effects and things, and that just adds on the time that it's taking to try to get rid of your symptoms. So you try another one and that just takes more time. So I think it's very time consuming as well.' (FG 4)

'My biggest problem was the fatigue. It was wearing me out, I mean, by four o'clock every afternoon I was ready to go to sleep. I mean, it took 2 or 3 different ones to get me where I need to be without feeling like I need to go to sleep whenever I need to be working or whatever. That was my biggest problem.' (FG 2)

Other promising benefits identified include the potential for improved effectiveness of any targeted therapies and the possibility of reducing trial and error attempts at appropriate prescribing and dosing.

'NNow] you have to take many different drugs. You would take one, and then you would have to wait a month to see if it worked or whether or not you tolerated it, or whether or not it worked for you. Sometimes it did, and sometimes it was a series of kind of hunt and peck to find out what's gonna work best for you. It was frustrating at times for me.' (FG 2)

'If you could take one test and end up taking one pill, and it's going to work versus spending the next 6 months testing every pill that didn't work, right there that genetic testing becomes worth it.' (FG 1)

Concerns about Personalized Medicine: Barriers and Risks

There was much discussion in all the focus groups surrounding a number of potential barriers and risks that the participants identified as being of paramount importance. In particular, as some of the quotes below demonstrate, analytical validity, clinical validity, and clinical utility of the information provided by testing to improve health outcomes were of paramount concern.

'This is all based on the premise: does DNA really tell us everything? I mean, that's really a core thing. Does your DNA determine your absorption?' (FG 1)

'How does it work for me? I would want to know how it would work for me. How is it going to work for me as opposed to something else you've shown through testing that isn't going to work for me?' (FG 2)

'Well, the only thing I really care about is how accurate the test is.' (FG 4)

'I would want to know, what are the chances of getting a false positive or a false negative? Telling you that you can take this drug, and then the test be wrong. What are the chances of that?' (FG 2)
'Say if there was only a 50:50 chance that the test results were true. I mean, I would think I would need at least 70:30.' (FG 2)

'I'd be more concerned about where I was having the test run. I mean, what is their training, their experience?' (FG 4)

'What we need to know is how many tests did they run before they sent the official results to the doctor? Because if you can't get the same results at least 3 times, then there is something wrong with your procedures.' (FG 3 )

'I think these tests should be really monitored. I mean, I think these tests would be the kind to be double-checked on. I mean you would do it and make sure you got the same results 2 times.' (FG 2)

Participants expressed doubt regarding access to testing and availability of pharmacogenomic-based diagnostic and associated therapeutics.

'But important too is: Who gets the test? Is it only people with money? Who is excluded from the test?' (FG 3)

'The cost and availability. ... certain technologies may only be at certain places, like here at the medical center? And not in more rural areas or something like that? It's not like you can go to a community clinic with no insurance and say, "I want this test. Do it now." '(FG 2)

'[T]here's certain parts of the population that's going to be disproportionately tested, you know. So maybe we're not looking for all the aspects that might, you know, if we might have 5,000 West Virginia coal miners versus 5,000 innercity Chicago youth, you know, versus 50 millionaires from Houston.' (FG 1)

'What happens if you've been on [a drug], and you're doing fine, and they discontinue it?' (FG 2)

There was a considerable degree of discussion about issues surrounding disclosure, privacy, and confidentiality.

'The privacy issue's gonna be a major priority, major priority.' (FG 1)

'Who uses that information? I doubt the HIPA A act will prevent who gets it?' (FG 3)

'And if they share this kind of stuff with your life insurance company, and they raise your rates on that too. I just took a test to get some life insurance, how crazy is this? And it's a policy where you pay a hundred dollars a month and you invest the money, but you still have a 150,000 dollar life insurance, but because I come back with high cholesterol and high blood pressure, it's affecting how much interest I get off the money now. So when I'm 55 years old, if I was in perfect health, then I get 60,000 dollars. I'm 37 now, now that I have this, I only get 27,000 dollars. I made 5,000 off my investments 
instead of 30,000-40,000 because of my cholesterol.' (FG 1)

Discussion surrounding issues related to insurability and costs was also animated in all the groups.

'Who gets that information? I mean, that guy that's paying the bill, the insurance company is gonna have full access.' (FG 1)

'But the insurance companies ought to get on board. If we can cure your high blood pressure by finding the right pill, even if that pill costs 50 bucks a day, versus not finding it and not doing anything, and then you having a massive stroke, need 6 months of rehab and have to renovate your house so you can get around, the insurance companies ought to get on board. And say, "We can save ourselves a pile of money by finding out now how to treat him to prevent that."' (FG 1)

'Ok, so maybe the testing is expensive but over a course of time you wouldn't be going through the cost of the different drugs, the cost of the different office visits, so it might end up balancing out or saving money in the long run.' (FG 2)

'If the insurance company is paying for it, the insurance company has the right to know.' (FG 1)

'Let them know I had the test, I mean, they have to know to pay, but they don't need to know my results.' (FG 2)

'We know that the insurance companies don't dictate what's covered, it's your employer that dictates what's covered. Is your employer going to sit down and restrict access to this test because of the cost associated, and what that would mean in formularies for the pharmacy and access?' (FG 4)

\section{Willingness to Pay}

A number of participants expressed willingness to pay out-of-pocket for testing provided that pharmacogenomic-based testing could offer valid and reliable information that would influence treatment decisions. It should be noted that although willingness to pay is generally considered a structured health economic concept, in this study we are limiting use of this term to the more commonly accepted lay understanding derived from the questions, 'Would you be willing to pay for pharmacogenomic testing?' and, 'How much would you be willing to pay for pharmacogenomic testing?'

Not surprisingly, willingness to pay was dependent on the severity of the disease or condition in question, with patients arguing that they would be willing to pay more for pharmacogenomic testing that would inform decisions regarding treatment options for colorectal cancer than for testing to inform decision-making regarding prescribing options for hypercholesterolemia.

'Some illnesses that, even for high cholesterol, I don't think I would test for that. But as it gets more serious, it's more likely that I would have it done.' (FG 4)

\section{Consumer Demand}

Several participants (about 68\%) expect that there will be consumer demand for pharmacogenomic-based testing and prescribing.

'How many of us bought a 400 dollar VCR back in 1981? Now you can get one for 30 bucks. I mean, sooner or later Wal-Mart is going to open a clinic to test genetics.' (FG 1)

'I guess if it were the only drug, I would want to try it anyway.' (FG 2)

\section{Discussion}

The successful integration of pharmacogenomic diagnostics and targeted therapeutic combinations in health care delivery depends, in part, on whether or not patients and the public at large are ready and willing to adopt these novel genomic technologies. This study, which is part of a larger, more quantitatively comprehensive project, explored patients' understanding and perspectives of pharmacogenomics-based diagnostics and their use to provide information to decide upon and select targeted treatment options in general as well as for 2 specific conditions: hypercholesterolemia and colorectal cancer.

In this study, we found that the use of genomic diagnostics and targeted therapeutics to facilitate personalized medicine has considerable support from patients (i.e., potential consumers of personalized medicine). The result is in line with the findings of previous studies on genetic testing (albeit not specifically related to pharmacogenomics), indicating acceptance of genetic testing, particularly among patients who are ill or at-risk persons [13-15].

However, our data revealed that participants were concerned with issues surrounding privacy and confidentiality of genetic test results, particularly with respect to access of information by insurers or employers. This finding validates previous hypotheses by us $[16,17]$ and others $[18,19]$. It should be noted, however, that most of the patients in this study generally had an oversimplified understanding of pharmacogenomics and how much of a role genetic variation plays in drug metabolism, drug responsiveness, and toxicity. For example, only 5 focus 
group participants indicated an awareness of the role of other (non-genetic) environmental factors in drug metabolism.

We also found that patients are very concerned with the accuracy of pharmacogenomic-based test results, and indeed this issue surfaced as a top priority for the majority of patients who participated in our study. This novel result provides evidence that patients recognize the importance of ascertaining analytical and clinical validity of genomic diagnostics prior to their widespread use in clinical practice. Remarkably, despite insisting on the importance of accuracy and validity of pharmacogenomicbased diagnostic tests, many participants felt that if the information provided by testing revealed the lack of an available appropriate drug, they would nevertheless opt to try any available drug. This finding suggests a potential added challenge for implementing clinical practice guidelines and policies for using pharmacogenomicbased testing for evidence-based prescribing and decision making regarding treatments.

Participants expressed concern about the potential costs of pharmacogenomic-based testing and how this might influence access to and availability of testing among various populations. This result confirms the findings of a recent study which explored public perspectives of so-called tailor-made drugs in Iceland but did not specifically assess the use of pharmacogenomics-based testing per se and found that participants were pre-occupied with issues of expenditure and their expectation that increased costs would results in local and global inequities [20].
In our study, questions regarding willingness to pay revealed that patients would be more willing to pay outof-pocket if the disease associated with pharmacogenomic testing for treatment was perceived to be high risk (e.g., breast cancer) versus a chronic condition that was perceived as lower risk (e.g., high cholesterol). Given that willingness to pay can be considered a measure of benefit or willingness to adopt novel medical technologies [21, 22], thus perceived severity of disease or illness can clearly influence patients' acceptance of and willingness to adopt novel pharmacogenomics-based testing and targeted therapeutics.

It is noteworthy, however, that test specificity and sensitivity, as ascertained by probing questions and discussions related to accuracy, validity, and reliability, remained the highest priority identified by participants regardless of disease severity.

As the personalized medicine approach is increasingly incorporated into health care, understanding patient acceptance of and readiness to adopt novel pharmacogenomics-based tests and therapeutics will become progressively more important for the development of appropriate health policies.

\section{Acknowledgements}

This study was funded by a grant from the Greenwall Foundation to Dr. Amalia M. Issa.

\section{References}

1 Vogel CL, Cobleigh MA, Tripathy D, Gutheil JC, Harris LN, Fehrenbacher L, Slamon DJ, Murphy M, Novotny WF, Burchmore M, Shak S, Steart SJ, Press M: Efficacy and safety of trastuzumab as a single agent in firstline treatment of HER2-overexpressing metastatic breast cancer. J Clin Oncol 2002;20: 719-726.

2 Cohen MH, Moses ML, Pazdur R: Gleevec for the treatment of chronic myelogenous leukemia: US Food and Drug Administration regulatory mechanisms, accelerated approval, and orphan drug status. Oncologist 2002;7:390-392.

$\checkmark 3$ Evans WE, Relling MK: Moving towards individualized medicine with pharmacogenomics. Nature 2004;429:464-468.
4 Lindpaintner K: Pharmacogenetics and the future of medical practice. J Mol Med 2003; 81:141-153.

5 Tsai YJ, Hoyme HE: Pharmacogenomics: the future of drug therapy. Clin Genet 2002;62: 257-264.

-6 Zineh I, Gerhard T, Aquilante CL, Beitelshees AL, Beasley BN, Hartzema AG: Availability of pharmacogenomics-based prescribing information in currently approved drugs. Pharmacogenomics J 2004;4: 354-358.

7 Freudenberg-Hua Y, Freudenberg J, Winantea J, Kluck N, Cichon S, Bruss M, Propping P, Nothen MM: Systematic investigation of genetic variability in 111 human genes - implications for studying variable drug response. Pharmacogenomics J 2005;5:183192.
8 Issa AM: Clinical applications of pharmacogenomics to adverse drug reactions. Exp Rev Clin Pharmacology 2008;1:251-260.

-9 Schrag D: The price tag on progress - chemotherapy for colorectal cancer. N Engl J Med 2004;351:317-319.

10 Quinn Patton M: Qualitative Research and Evaluation Methods, ed 3. Thousand Oaks, Sage Publications, 2002.

11 Neuman WL: Basics of Social Research: Qualitative and Quantitative Approaches. Boston, Pearson, 2007.

12 Strauss A, Corbin J: Grounded theory in practice. London, Sage Publications, 1997.

13 Berth H, Balck F, Dinkel A: Attitudes toward genetic testing in patients at risk for HNPCC/ FAP and the German population. Genet Test 2002;6:273-280 
14 Sorenson JR, Cheuvront B, DeVellis B, Callanan N, Silverman L, Koch G, Sharp T, Fernald G: Acceptance of home and clinic-based cystic fibrosis carrier education and testing by first, second, and third degree relatives of cystic fibrosis patients. Am J Med Gen 1997; 70:121-129.

15 Cappelli M, Surh L, Humphreys L, Verma S, Logan D, Hunter A, Allanson J: Measuring women's preferences for breast cancer treatments and BRCA1/BRCA2 testing. Qual Life Res 2001;10:595-607.
16 Issa AM: Ethical considerations in clinical pharmacogenomics research. Trends Pharmacol Sci 2000;21:247-249.

17 Issa AM: Perspectives in pharmacogenomic profiling in the drug development process. Nat Rev Drug Discov 2002;1:300-308.

18 Nebert DW, Bingham E: Pharmacogenomics: out of the lab and into the community. Trends Biotechnol 2001;19:519-523.

19 Thomas SM: Pharmacogenetics: the ethical context. Pharmacogenomics J 2001;1:239242.
20 Almarsdottir AB, Bjornsdottir I, Traulsen JM: A lay prescription for tailor-made drugs - focus group reflections on pharmacogenomics. Health Policy 2005;71:233241.

21 Gafni A: Willingness-to-pay as a measure of benefits: relevant questions in the context of public decision making about health care programs. Med Care 1991;29:1246-1252.

22 Dranitsaris G: A pilot study to evaluate the feasibility of using willingness to pay as a measure of value in cancer supportive care: an assessment of amifostine cytoprotection. Support Care Cancer 1997;5:489-499. 